\title{
Nonvesicular Lipid Transfer from the Endoplasmic Reticulum
}

\author{
Sima Lev \\ Molecular Cell Biology Department, Weizmann Institute of Science, Rehovot 76100, Israel \\ Correspondence: sima.lev@weizmann.ac.il
}

The transport of lipids from their synthesis site at the endoplasmic reticulum (ER) to different target membranes could be mediated by both vesicular and nonvesicular transport mechanisms. Nonvesicular lipid transport appears to be the major transport route of certain lipid species, and could be mediated by either spontaneous lipid transport or by lipid-transfer proteins (LTPs). Although nonvesicular lipid transport has been extensively studied for more than four decades, its underlying mechanism, advantage and regulation, have not been fully explored. In particular, the function of LTPs and their involvement in intracellular lipid movement remain largely controversial. In this article, we describe the pathways by which lipids are synthesized at the ER and delivered to different cellular membranes, and discuss the role of LTPs in lipid transport both in vitro and in intact cells.

$\mathrm{T}_{\mathrm{t}}^{\mathrm{h}}$ he endoplasmic reticulum (ER) is a large interconnected membrane network that plays a major role in lipid biosynthesis in eukaryotic cells (Borgese et al. 2006). Newly synthesized lipids at the ER are then delivered to different cellular membranes or organelles, each of which shows unique lipid and protein composition and executes distinct cellular function (Holthuis et al. 2003). The transport of lipids from the ER can be mediated by both vesicular and nonvesicular transport mechanisms. Vesicular transport, as opposed to nonvesicular lipid transport, requires metabolic energy, intact cytoskeleton, and connection to the vesicular transport machinery (Kaplan and Simoni 1985a; Voelker 1990; Vance et al. 1991). Although vesicular lipid transport mediates the bulk transport of many lipids, increasing lines of evidence suggest that nonvesicular lipid transport is the major trans- port route for certain lipid types (Lev 2010). Nonvesicular lipid transport between membranes could be mediated by spontaneous lipid transport, in which a lipid monomer is diffused through the cytosol from a donor to the acceptor membrane. Given that most cellular lipids are highly hydrophobic, their diffusion through an aqueous phase is very slow and insufficient to support substantial transport of most lipids (Jones and Thompson 1989; Mesmin and Maxfield 2009). Nevertheless, spontaneous lipid transport can be greatly facilitated at membrane contact sites (MCSs) (Levine 2004; Holthuis and Levine 2005) and/or by lipid-transfer proteins (LTPs) (Lev 2010). MCSs are defined as small cytosolic gaps of $10-20 \mathrm{~nm}$ between the ER membranes and virtually all cellular organelles (Levine 2004; Lebiedzinska et al. 2009), whereas LTPs are intracellular proteins that can carry a

Editors: Susan Ferro-Novick, Tom A. Rapoport, and Randy Schekman

Additional Perspectives on The Endoplasmic Reticulum available at www.cshperspectives.org

Copyright (C) 2012 Cold Spring Harbor Laboratory Press; all rights reserved; doi: 10.1101/cshperspect.a013300

Cite this article as Cold Spring Harb Perspect Biol 2012;4:a013300 
lipid monomer in a hydrophobic pocket and transfer it between membranes through an aqueous phase. LTPs were initially discovered as soluble factors that accelerate the exchange or net transfer of different lipid species between membranes in vitro (Wirtz and Zilversmit 1968). Subsequently, many LTPs have been isolated, cloned, and crystallized. LTPs have been identified in all eukaryotes, in plants, and in bacteria, and according to their sequence and structure similarity have been subdivided into different protein families including SEC14, PITP (phosphatidylinositol-transfer protein), START (StAR-related lipid transfer), GLTP (glycolipid transfer protein), SCP-2 (nonspecific LTPs), and OSBP (oxysterol-binding protein)/ORP (OSBP-related proteins) (D’Angelo et al. 2008). In general, LTPs show specificity for one or more lipid types, and may contain only a single lipid-transfer domain (LTD), or additional structural domains with varying functions (Lev 2010). Over the past 40 years, LTPs have been extensively studied and the major principles of their action mode have been established from both biophysical measurements in vitro and structural data (Lev 2010). Nevertheless, the precise function of LTPs in intact cells remains controversial and a subject of an active field of research. In this article, we briefly describe how lipids are synthesized in the ER and delivered to different target membranes, and discuss how LTPs influence lipid transport in vitro and in intact cells.

\section{DE NOVO LIPID BIOSYNTHESIS IN THE ER}

Several organelles are involved in lipid biosynthesis in eukaryotic cells, including the ER, the mitochondria, and the peroxisomes. The mitochondria and peroxisomes are responsible for cardiolipin, phosphatidylglycerol, and plasmalogens biosynthesis, respectively, whereas the ER is the major site for biosynthesis of most membrane lipids. It contains multiple biosynthetic enzymes that catalyze the initial steps of de novo biosynthesis of glycerophospholipids (GPLs), sphingolipids, and sterols, the three major lipid classes in eukaryotes (Sprong et al. 2001).

Biosynthesis of Glycerophospholipids: GPLs are the most abundant structural lipids in biological membranes. Various GPLs can be produced in different membrane compartments by specific enzymes that modulate their head groups or fatty acyl chains. Yet, de novo biosynthesis of the four major GPLs in eukaryotes: phosphatidylcholine (PC), phosphatidylethanolamine (PE), phosphatidylserine (PS), and phosphatidylinositol (PI), initiates at the ER from the same precursor; phosphatidic acid (PA) (Hermansson et al. 2011). PA is produced by two sequential acylation reactions of glycerol 3-phosphate that are mediated by the two acyltransferases: glycerol phosphate acyltransferase (GPAT) and acylglycerol-phosphate acyltransferase (AGPAT). Further biosynthetic reactions assemble the four different head groups to produce PC, PE, PS, and PI (Fig. 1).

Phosphatidylcholine (PC) is the most abundant GPL in eukaryotic membranes. It typically carries one saturated and one unsaturated fatty acyl chain, and has a cylindrical shape owing to its large polar head (van Meer et al. 2008). Two pathways mediate PC biosynthesis in mammals; the CDP-choline pathway (Kennedy), which is used by all cell types and takes place at the ER, and the methylation pathway, which exclusively occurs in hepatocytes, takes place in the mitochondria, and is mediated by sequential methylation reactions of PE (Fagone and Jackowski 2009). The Kennedy pathway involves three sequential reactions: the first two occur at the ER and are mediated by choline kinase (CK) and CTP:phosphocholine cytidylyltransferase (CCT), the rate-limiting enzyme. CK phosphorylates choline to phosphocholine, which is then condensed to CTP by CCT to produce CDP-choline. Phosphocholine is then transferred from CDP-choline to diacylglycerol (DAG) by CDP-choline:diacylglycerol cholinephosphotransferase (CPT), which localizes in the Golgi and produces PC (Fig. 1) (Litvak et al. 2005).

Phosphatidylethanolamine (PE) is the second most abundant GPL in eukaryotes. PE can be produced by the CDP-ethanolamine pathway (Kennedy) in the ER and by the PS decarboxylation pathway in the mitochondria. The formation of PE via the PS decarboxylation pathway is mediated by the inner mitochondrial 
Lipid Transport from the ER
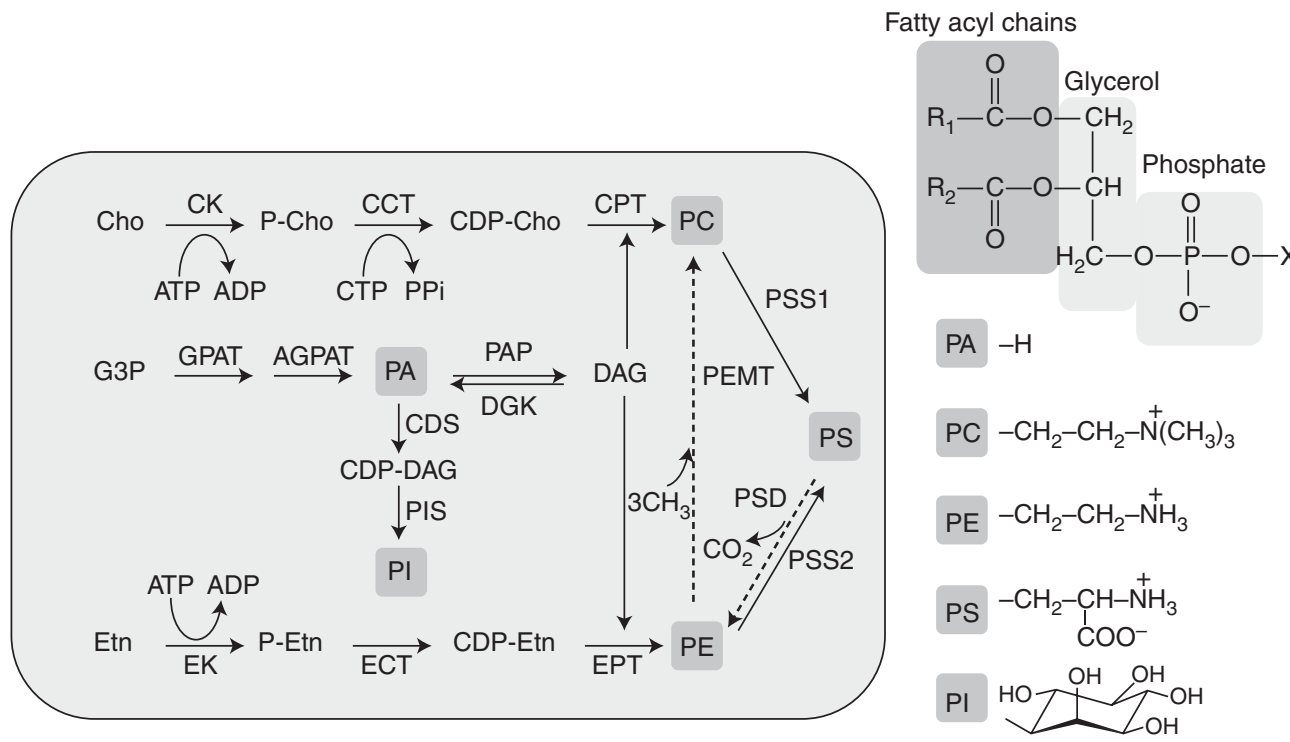

Figure 1. Biosynthesis of glycerophospholipids. All GPLs consist of a glycerol backbone, which is esterified to two fatty acids in its first and second carbons and to phosphoric acid in its third carbon. Different head groups (X) are attached to the phosphate group to yield PA, PC, PE, PS, and PI. The most common GPLs: PC, PE, PS, and PI are derived from PA, which is synthesized in the ER. De novo biosynthesis of PC and PE via the Kennedy pathway occurs at the ER and requires DAG, which is derived from PA by PA phosphatase (PAP). DAG kinase (DGK) phosphorylates DAG back to PA. PI synthesis also requires PA, whereas PS synthesis is mediated by PSS1 and PSS2 at the MAM fraction. Dashed arrows represent biosynthetic steps that take place at the mitochondria. Cho, choline; Etn, ethanolamine; G3P, glycerol 3-phosphate.

membrane enzyme PS decarboxylase (PSD) and seems to account for most PE synthesis in mammalian cells. The Kennedy pathway is mediated by three sequential reactions, similar to those that are involved in PC biosynthesis, including phosphorylation of ethanolamine by ethanolamine kinase (EK) to produce phosphoethanolamine, condensation of phosphoethanolamine to CTP by CTP:phosphoethanolamine cytidylyltransferase (ET) to produce CDP-ethanolamine, and finally, transferring of phosphoethanolamine to DAG, by CDP-ethanolamine:diacyl glycerol ethanolaminephosphotransferase (EPT) (Fig. 1) (Vance and Steenbergen 2005; Vance 2008).

Phosphatidylserine (PS): The formation of PS in mammalian cells occurs through the exchange of L-serine with either the choline moiety of PC or the ethanolamine moiety of PE, and is catalyzed by two different enzymes: PS synthase 1 (PSS1) and PSS2, respectively (Stone and Vance 2000). These integral membrane en- zymes are highly enriched in a subcompartment of the ER that associates with the mitochondria and terms the "mitochondria-associated membranes" MAM fraction. The newly synthesized PS at the MAM is transported into the mitochondrial intermembrane space, where it undergoes decarboxylation by PSD to produce $\mathrm{PE}$ as described above. This nonvesicular transport of PS from the ER to the mitochondria shows the importance of the MAM, an MCS, in regulating cellular lipid biosynthesis and distribution (Lev 2010).

Phosphatidylinositol (PI): The first step in PI biosynthesis is mediated by CDP-DAG synthase (CDS), which localizes at the ER and catalyzes the formation of CDP-DAG from PA and CTP. Subsequently, PI synthase (PIS) catalyzes the production of PI from CDP-DAG and myoinositol (Fig. 1) (Antonsson 1997).

PIS is a peripheral membrane protein that associates mainly with the ER. Recent studies, however, proposed that PIS is localized on a 
specialized membrane compartment that is derived from the ER and makes ample contacts with other cellular membranes including the plasma membrane (PM), suggesting that PI could be synthesized at the PM (Kim et al. 2011). This might be critical for many cellular responses especially because PI is a precursor of various phosphoinositide species (PI3P, PI4P, PI5P, PI[3,4]P2, PI[3,5]P2, PI[4,5]P2, PI $[3,4,5] \mathrm{P} 3)$. Many phosphoinositides play central roles in different signal transduction cascades and membrane trafficking pathways (Odorizzi et al. 2000; Toker 2002); some of them act as second messengers, substrates, or activators of many enzymes, modulators of structural proteins, and targeting components for various cellular proteins (Balla et al. 2009). Hence, the local levels of phosphoinositides at different membrane compartments are critical for key cellular processes, and must be tightly controlled by mechanisms that regulate their turnover and production from PI.

Sphingolipids are synthesized de novo via a common backbone (sphinganine) that is modified to produce ceramide and more complex phospho- and glycosphingolipids. Sphingolipids biosynthesis initiates at the ER and continues at the Golgi complex (Merrill 2002). The first biosynthetic step is mediated by serine palmitoyltransferase (SPT), the rate-limiting enzyme that catalyzes the formation of 3-ketodihydrosphingosine (KDS) from serine and palmitoyl CoA. Subsequent steps lead to the formation of ceramide in mammalian cells (Hanada 2003), which is then transferred to the Golgi, where it can be converted into sphingomyelin (SM), glucosylceramide (GlcCer), lactosylceramide (LacCer), and more complex glycosphingolipids. SM synthase (SMS) at the luminal leaflet of the trans-Golgi catalyzes the production of SM by transferring phosphocholine from PC to ceramide, GlcCer synthase catalyzes the production of GlcCer from ceramide and UDP-glucose, and subsequently LacCer synthase synthesizes LacCer from GlcCer (Fig. 2).

Sterols are ubiquitous components of all eukaryotes cell membranes. In mammals, cholesterol, the major structural membrane lipid, is highly enriched at the PM (Blom et al. 2011).
Mammalian cells produce their own cholesterol via de novo biosynthesis pathway that involves $>30$ enzymes (Tobert 2003). The first step in the pathway produces 3-hydroxy-3-methylglutaryl-CoA (HMG-CoA) from acetyl-CoA and acetoacetyl-CoA by HMG-CoA synthase. Subsequently, HMG-CoA is converted into mevalonate by HMG-CoA reductase, an integral ER membrane glycoprotein that catalyzes the ratelimiting step for the entire pathway. Mevalonate is the key and first intermediate of the pathway. Further steps are involved in the production of isoprene-based molecules, geranyl pyrophosphate (PP), farnesyl PP, squalene, and finally cholesterol (Fig. 3). The whole process is highly energy dependent and is strongly regulated by both posttranslational modifications and by transcriptional control (Simons and Ikonen 2000).

\section{NONVESICULAR LIPID TRANSPORT}

The production of multiple lipid species at the ER requires delivery systems that rapidly and efficiently transfer them to different target membranes. Both vesicular and nonvesicular lipid transport mediate intracellular lipid trafficking from the ER. Yet, inhibition of vesicular transport by pharmacological and genetic manipulations such as BFA or colchicine treatment, ATP depletion, and specific sec mutants (such as Sec18 mutant) has no effect on intracellular transport of certain lipid species (Kaplan and Simoni 1985b; Urbani and Simoni 1990; Heino et al. 2000; Baumann et al. 2005). Furthermore, imaging and biochemical studies using fluorescent lipid analogs, such as DHE (dehydroergosterol; a fluorescent cholesterol analog) and radioactive labels lipids, respectively, support the involvement of nonvesicular transport in intracellular lipid trafficking (Maxfield and Mondal 2006).

Nonvesicular lipid transport is mainly mediated by monomeric lipid exchange, in which a lipid monomer is transported through an aqueous phase from the outer leaflet of a donor membrane to the outer leaflet of an acceptor membrane. This process does not require metabolic energy and can either be spontaneous or 
Lipid Transport from the ER

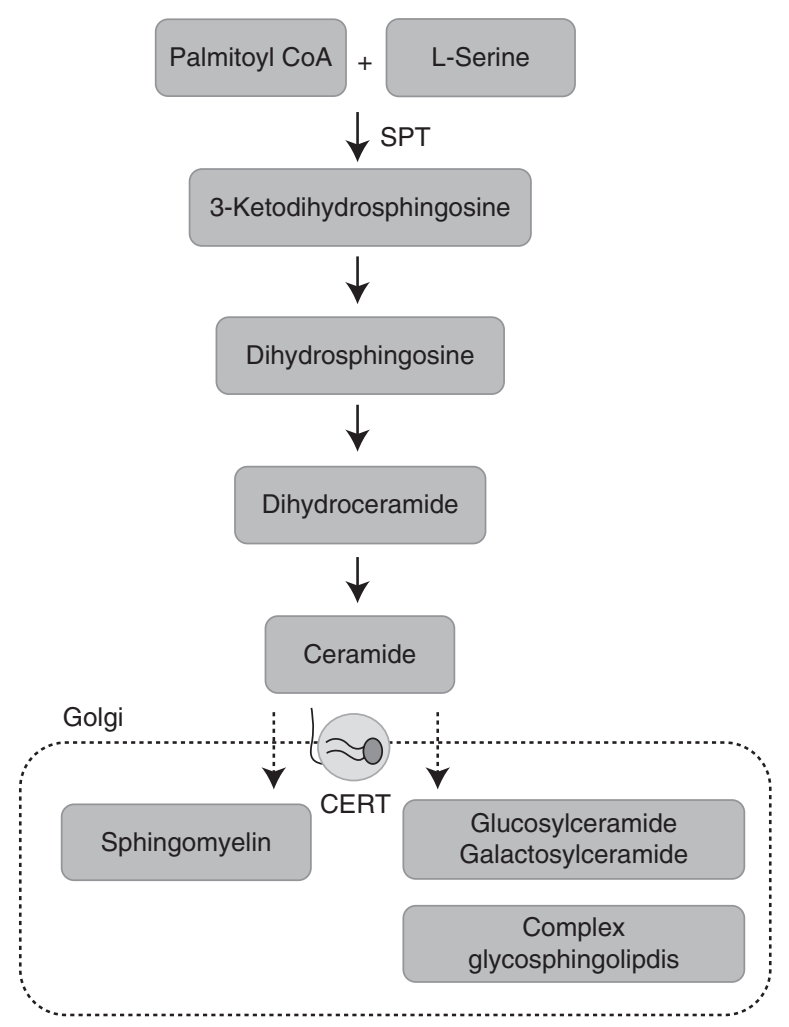

Figure 2. Sphingolipids biosynthesis in mammals. The first step in sphingolipid biosynthesis is catalyzed by serine palmitoyltransferase (SPT), the rate-limiting enzyme of the entire pathway. SPT catalyzes the condensation of serine and palmitoyl CoA to produce 3-ketodihydrosphingosine (KDS). The subsequent three synthetic steps result in the production of ceramide, the first compound with a bona fide sphingosine backbone (Blom et al. 2011). Ceramide is then transported to the Golgi by ceramide transfer protein (CERT), where it is metabolized into SM and glycosphingolipids.

LTP mediated (Fig. 4A). Spontaneous lipid transport is a slow process that can be markedly accelerated at MCSs and by LTPs (Lev 2010).

MCSs have been observed by both biochemical methods and electron microscopy in mammalian, yeast, fly, and plant cells (Shore and Tata 1977; Perkins et al. 1997; Ladinsky et al. 1999). These dynamic structures are highly enriched in lipid biosynthetic enzymes and LTPs, and are generally formed and/or stabilized by specialized tethering proteins (Fig. 4C) (Giorgi et al. 2009; Lebiedzinska et al. 2009). For example, the ERMES (ER-mitochondrion encounter structure) complex acts as an ER-mitochondria tether in yeast and was proposed to affect the lipid composition of the mitochondria membrane (Kornmann et al. 2009), but not the transport of PS from the ER to the mitochondria (Nguyen et al. 2012). The small GTPase Rab18 facilitates lipid droplet-ER association, and thereby may promote lipid transfer between these compartments (Ozeki et al. 2005). Mitofusin 2, a dynaminlike GTPase that is required for mitochondrial fusion, has also been implicated in ERmitochondria tethering in mammals (de Brito and Scorrano 2008). In plant, MCSs between the ER and the outer chloroplast membrane (PLAM; plastid-associated microsomes) promote the formation of monogalactosyl- and digalactosyl-diacylglycerol (MGDG and DGDG), the two prominent plant lipids that are synthesized in the chloroplast (Voelker 2009). Transport of PC from the ER to the outer chloroplast membrane occurs at the PLAM and is mediated, 


\section{S. Lev}

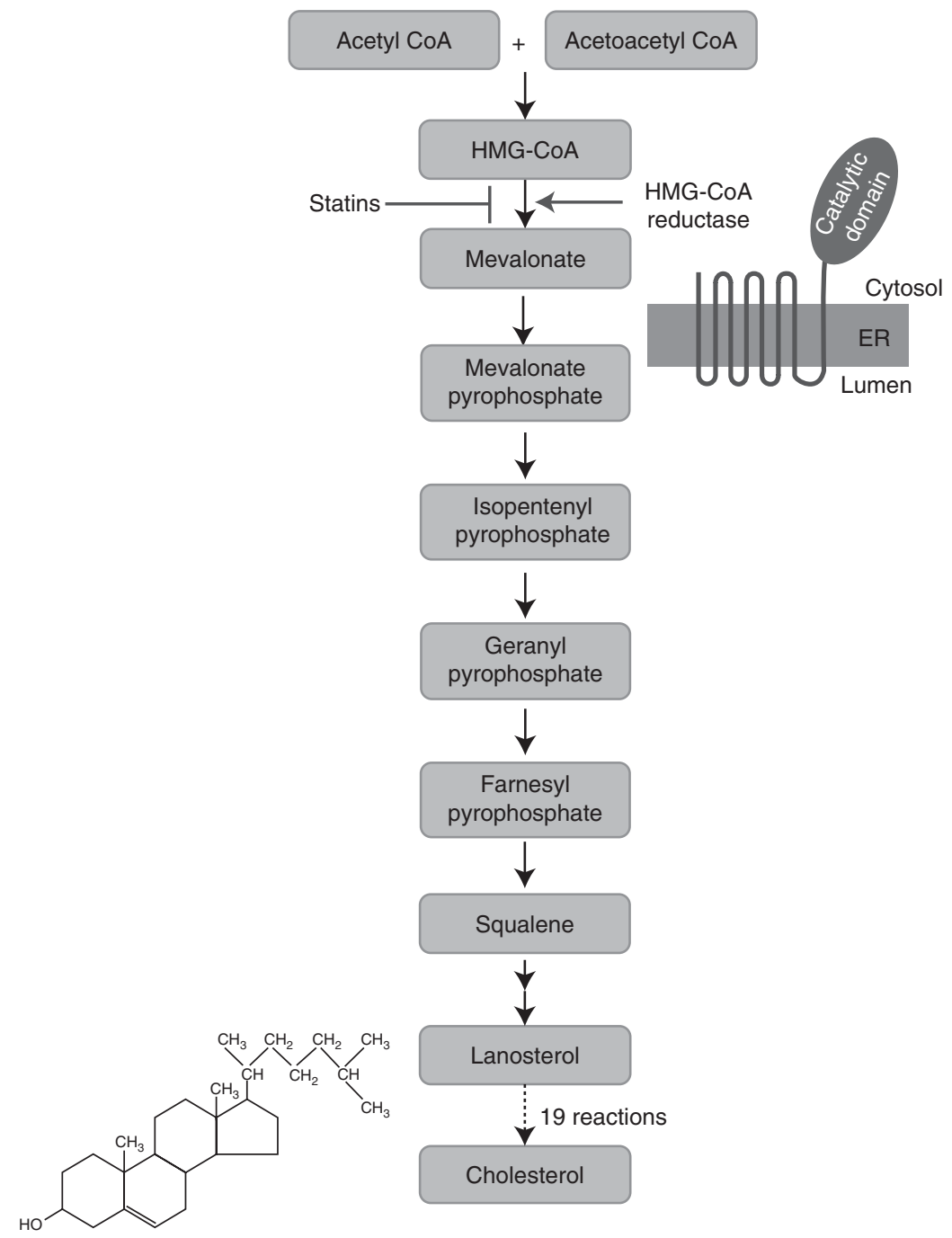

Figure 3. De novo biosynthesis of cholesterol. Cholesterol is a 27-carbon compound consisting of a four-ring structure with 17 carbon atoms, to which two methyl groups and an isooctyl side chain are attached. Cholesterol is made from acetyl-CoA in a process involving $>30$ enzymes. The process can be divided into four major stages. In the first stage, the three acetate units condense to form a six-carbon intermediate, mevalonate. This stage is catalyzed by three sequential reactions mediated by thiolase, HMG-CoA synthase, and finally by HMG-CoA reductase, an integral ER membrane protein that regulates the entire pathway and can be inhibited by statins. The second stage involves the conversion of mevalonate into activated isoprene units, and subsequently the polymerization of six five-carbon isoprene units to form the 30-carbon linear structure of squalene. Finally, cyclization of squalene leads to the formation of a four-ring structure, which undergoes further chemical modifications (oxidations, removal, or migration of methyl groups) to form cholesterol. Cholesterol serves as a precursor for other bioactive sterols, such as steroid hormones and oxysterols (Blom et al. 2011). The figure shows a simplified version of the pathway. 
A

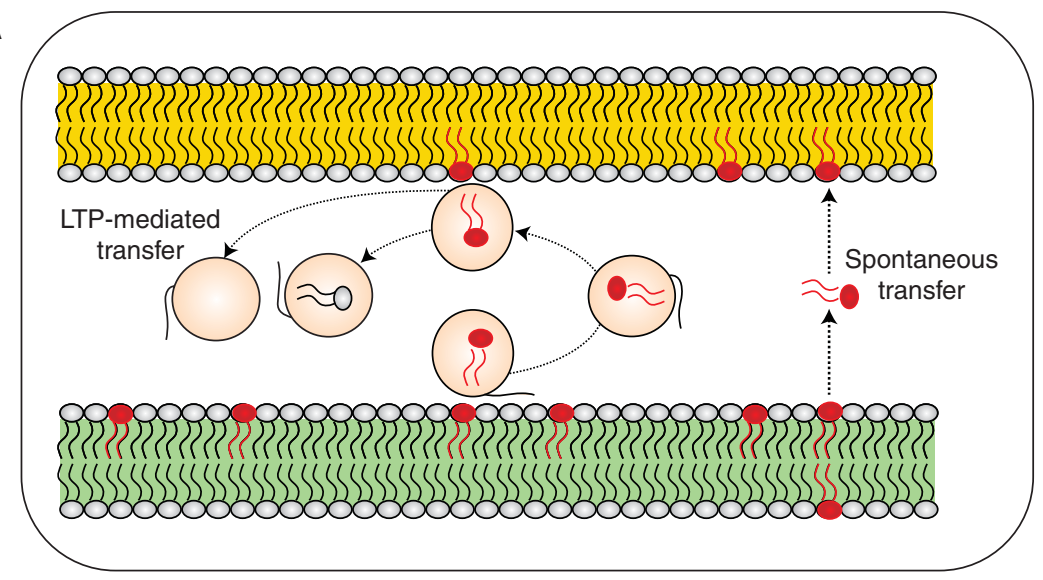

B
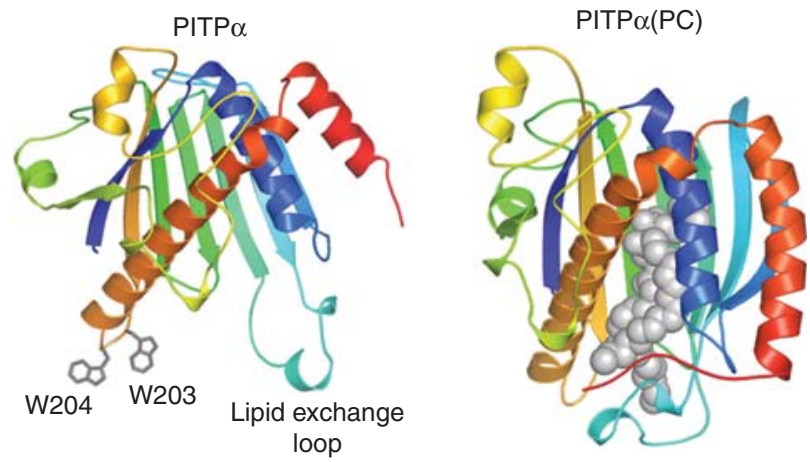

C
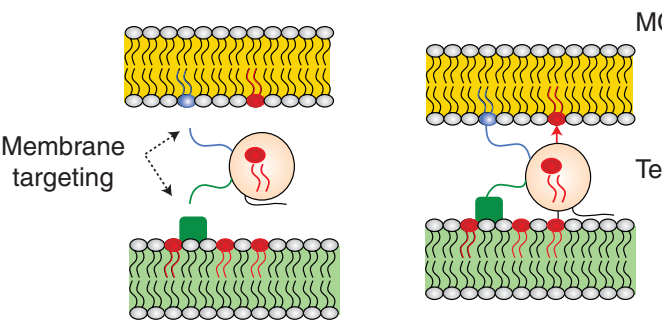

MCSs

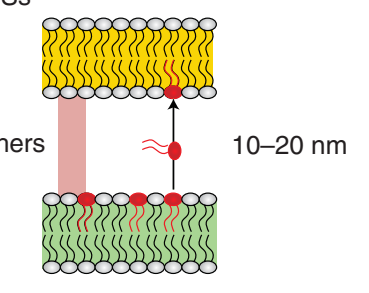

Figure 4. Nonvesicular lipid transport between membranes. (A) Lipid transport between membranes can be either spontaneous or LTP mediated. The transport of lipids by LTPs is mediated by sequential events: (1) The LTP interacts with a donor membrane, which triggers the opening of the lipid-binding cavity; (2) the lipid is then extracted from the bilayer; (3) the LTP dissociates from the donor membrane; and (4) diffuses through the aqueous phase in a closed conformation. (5) The LTP interacts with an acceptor membrane, which triggers (6) tunnel opening, and (7) lipid desorption. As shown, LTP can transfer a lipid to the acceptor membrane or exchange it with a lipid of the acceptor membrane. (B) A ribbon diagram of the open (Schouten et al. 2002) and the closed PC-bound conformation (Yoder et al. 2001) of PITP $\alpha$. The PC/PI binding site is formed by the concave surface of a central eight-stranded $\beta$ sheet and two helices. The lipid-exchange loop and the carboxyterminal tail act as a lid. Trp203 and Trp204 are crucial for membrane association and lipid-transfer activity (Tilley et al. 2004; Shadan et al. 2008). (C) Spontaneous or LTP-mediated nonvesicular lipid transport can be greatly facilitated at MCSs. These sites between the ER and virtually all other organelles are formed/stabilized by various tethering factors. LTPs with dual membrane targeting determinants may simultaneously interact with two membranes at MCSs. These membrane targeting determinants can recognize either lipid or protein molecules on their target membranes, and thereby can direct lipid transfer between specific cellular membranes. 
S. Lev

either directly or indirectly, by the ER-associated protein TGD4. PC is then hydrolyzed by phospholipase $\mathrm{D}$ (PLD) to produce PA, which is then converted into DAG in the inner membrane of the chloroplast and subsequently into MGDG and DGDG (Benning et al. 2006). Additional tethering factors of MCSs have been described previously (Lev 2010).

\section{NONVESICULAR LIPID TRANSPORT BY LTPS}

The ability of LTPs to accelerate lipid transport in vitro has been shown by numerous studies over the past 40 years (Lev 2010). The lipidtransfer activity of LTPs has been determined by in vitro lipid-transfer assays using either radiolabeled lipids or fluorimetric methods (Lev 2010). The transport of lipid from a radiolabeled donor membrane to an unlabeled acceptor membrane is generally monitored in the absence and the presence of an LTP, and is determined following separation of the two membrane compartments (liposomes, vesicles, microsomes, mitochondria) by differential centrifugation or by affinity capture methods (Lev 2010). In the fluorimetric assays, the time-dependent increase in the fluorescence reflects lipid-transfer activity (Rueckert and Schmidt 1990).

These in vitro studies suggest that LTPs markedly facilitate (several orders of magnitude) lipid transport between membranes, possibly by increasing the rate of lipid absorption from the bilayers (Lalanne and Ponsin 2000). Further structural, biochemical, and biophysical studies suggest that the lipid-transfer domain (LTD) of LTPs contains a hydrophobic lipid-binding tunnel that accommodates a single lipid molecule. In general, the structures are dominated by $\beta$-sheet motifs, such as $\beta$ barrels, $\beta$ cups, and $\beta$ grooves. Several $\alpha$-helices (2-4) are closely packed with central $\beta$-sheet motifs and together form a hydrophobic binding tunnel (Fig. 4B). Typically, a "lid" covers the hydrophobic tunnel and acts as a gate for lipid uptake and release (Im et al. 2005; Wirtz et al. 2006). The interaction of an LTP with membranes is thought to induce conformational changes, leading to displacement of the lid from the lipid-binding cavity and, consequently, tunnel opening (Lev 2010).
Thus, LTPs may exist in two distinct conformations: a "closed" conformation, which reflects a transport-competent conformation in which one lipid molecule is enclosed in the tunnel and an "open," membrane-bound conformation (Fig. 4B) (Im et al. 2005; Wirtz et al. 2006). In the closed conformation the lid is often stabilized by hydrogen bonds and hydrophobic interactions with the rest of the protein. Polar interactions between the lid and the membrane phospholipids could facilitate the opening of the tunnel and stabilize membrane anchoring. Indeed, truncation of the lid in various LTPs markedly affects their ability to interact with membranes and abolishes their lipidtransfer activity (Prosser et al. 1997; Tremblay et al. 1998; Feng et al. 2000). In some cases, the lid penetrates the bilayer and helps to scoop the lipid out of the membrane into the lipid-binding cavity (Sha et al. 1998), thereby facilitating lipid absorption. Hence, the transport of lipids by LTPs could be mediated by sequential events involving the interaction with a donor membrane and the opening of the lipid-binding tunnel, extraction of a lipid from the bilayer, dissociation from the donor membrane, and diffusion through the aqueous phase in a closed conformation. The transport is terminated by interaction with an acceptor membrane, tunnel opening, and lipid desorption (Fig. 4A).

\section{PRINCIPLES OF LIPID TRANSPORT BY LTPS}

Although LTPs were first described as proteins that accelerate a net lipid transfer between donor and acceptor membranes down the lipid concentration gradient (Rueckert and Schmidt 1990; Holthuis and Levine 2005), it became evident that LTPs do not mediate a simple vectorial lipid transport between membranes. Instead, LTPs use their lipid-transfer activity to modulate the lipid content of membranes according to their local membrane environment. The lipid type and its surface concentration as well as additional parameters including the lipid composition of the donor and acceptor membranes, their charge, curvature, size, and fluidity, influence lipid transport by LTPs (Helmkamp 1986; Nichols 1988; Gadella and Wirtz 
Lipid Transport from the ER

1994). The membrane association and dissociation steps (donor and acceptor) mostly depend on physical parameters such as membrane charge, curvature, and size (Nichols 1988; Gadella and Wirtz 1994). In some cases, the association of LTPs with specific membranes is mediated by membrane targeting determinants that present on the LTD or on other structural domains. These targeting determinants can interact with either membrane proteins or lipid molecules (Fig. 4C), and can markedly contribute to the specificity and the direction of the lipid transport event (Lev 2010). The lipid absorption step mainly depends on the lipid type and its surface concentration, but could also be affected by membrane fluidity and curvature; higher lipid absorption is generally observed with more fluid or with highly curved membranes. The diffusion time of the LTP through the cytosol correlates with the distance between the donor and acceptor membranes (Levine 2004), and could be greatly reduced if the two membranes are found in close apposition to each other; at MCSs. The combined influence of these parameters on LTP-mediated lipid transport has been shown in many studies. For example, the LTD of the yeast ORP, Osh4, contains at least two membrane-binding surfaces that bind phosphoinositides, one near the mouth of the sterol-binding pocket and another at a distal site that binds PI(4,5)P2 (Schulz et al. 2009). The transport of sterol by Osh4 is enhanced when $\mathrm{PI}(4,5) \mathrm{P} 2$ is present on the acceptor membrane. PI $(4,5) \mathrm{P} 2$ may, therefore, enhance the directional transport of sterol from PI(4,5)P2-poor to PI(4,5)P2-rich membranes. Likewise, in vitro cholesterol transport by OSBP and ORP9, which bind PI4P via their pleckstrin homology $(\mathrm{PH})$ domain (Levine and Munro 1998), is markedly stimulated by the presence of PI4P (Ngo and Ridgway 2009). These examples show how the membrane environment of different LTPs (PI[4,5]P2 content for Osh4 and PI4P for OSBP and ORP9) influences their lipid (sterol) transfer activity.

Although most of these principles have been established through in vitro studies, many of them are likely relevant for LTP-mediated lipid transfer in intact cells.

\section{NONVESICULAR TRANSPORT OF SPHINGOLIPIDS AND STEROLS IN INTACT CELLS}

Newly synthesized sterols and ceramide at the ER are mainly transported via nonvesicular transport pathways in both mammals and yeast. In mammalian cells, ceramide is synthesized in the ER and primarily transported by ceramide transfer protein (CERT) to the Golgi complex, where it is converted into SM by SMS (Pagano 1988). CERT was originally discovered as a protein that restored SM synthesis of LY-A cells, a mutant CHO cell line (Hanada 2003). The reduced levels of SM in LY-A cells result from a defect in ER to the Golgi ceramide transport owing to a point mutation in the $\mathrm{PH}$ domain of CERT (Gly67Glu) that abrogates its PI4P binding and, consequently, its Golgi targeting. Hence, CERT transports ceramide from the ER to the Golgi according to the PI4P content of the Golgi membranes (Hanada et al. 2003; Kawano et al. 2006). CERT also contains a FFAT (two phenylalanines in an acidic tract) motif (Loewen et al. 2003) that mediates its interaction with the ER membrane proteins of the VAP family (VAP-A and VAP-B) (Lev et al. 2008), and a START domain that binds and transfers ceramide (Kudo et al. 2008). Thus, CERT has dual membrane targeting determinants that mediate its interaction with the ER and the Golgi membranes. Mutations in either the PH domain or the FFAT motif of CERT impair ER-to-Golgi ceramide transport (Hanada et al. 2003; Kawano et al. 2006), suggesting that ceramide transport is spatially restricted to ER-Golgi-MCSs. Interestingly, ceramide transport in yeast also occurs at the ER-Golgi-MCSs (Funato and Riezman 2001) by as-yet-unclear mechanisms, as a yeast homolog of CERT has not been identified. The transport of ceramide from the ER to the Golgi is also essential for glycosphingolipid (GSL) production at the luminal leaflet of the transGolgi, and involves two LTPs: CERT and FAPP2. CERT transfers ceramide and therefore is essential for GlcCer production by GlcCer synthase, and FFAP2 transfers GlcCer and is essential for the subsequent production of GSLs (D'Angelo et al. 2007; Halter et al. 2007). 
S. Lev

The transport of sterols from the ER is unaffected by drugs or genetic mutations that block vesicular transport, and is thought to be mediated mainly by spontaneous lipid transfer and by certain LTPs (Urbani and Simoni 1990; Heino et al. 2000; Maxfield and Wustner 2002; Baumann et al. 2005). Although sterols are highly hydrophobic lipids their spontaneous movement between certain membranes could be very rapid (a half-time of $1 \mathrm{~min}$ or less) (Dawidowicz 1987), and can thereby support substantial sterol transport between specific membranes. Sterol-transfer proteins may also mediate nonvesicular transport of sterols in yeast and mammals. Several candidates might be involved, including OSBP and ORPs in mammals and Osh (OSBP homologs) proteins in budding yeast (Lehto and Olkkonen 2003), as well as the mammalian StAR (steroidogenic acute regulatory) protein and its related STARTs. It is not currently clear whether these LTPs function as sterol transporters in intact cells, or have different regulatory functions (Alpy and Tomasetto 2005; Maxfield and van Meer 2010; Raychaudhuri and Prinz 2010).

StAR, the prototype for the START proteins, plays a crucial role in steroidogenesis by facilitating the delivery of cholesterol from the outer to the inner mitochondrial membrane, where the first step in steroid biosynthesis is catalyzed (Alpy and Tomasetto 2005). It can transfer cholesterol between membranes in vitro, and robustly transfers cholesterol within steroidogenic cells ( $\sim 400$ molecules of cholesterol into the mitochondria per minute [Ikonen and Jansen 2008]). STARD4 is an abundant steroltransfer protein composed of only a START domain. Its overexpression enhances cholesterol esterification, possibly by increasing cholesterol transport to the ER and consequently its estrification by ACAT (cholesterol acyl-transferase) (Rodriguez-Agudo et al. 2008). Overexpression of STARD4 also accelerates sterol transport from the PM to the endocytic recycling compartment (ERC) (Mesmin et al. 2011), suggesting that STARD4 functions as a sterol transporter in intact cells. ORP2 was also proposed to function as an ER-PM sterol transporter, as its overexpression enhanced efflux of newly syn- thesized cholesterol from the ER (Hynynen et al. 2005).

The function of OSBP, most ORPs, and the Osh proteins as sterol transporters is controversial. Some studies suggest that the yeast Osh proteins mediate intracellular sterol transport, as a yeast strain deficient of all the seven Osh proteins shows a significant reduction in PM-ER sterol transfer (Raychaudhuri et al. 2006; Sullivan et al. 2006). Other studies, however, suggest that Osh proteins regulate sterol transport indirectly by affecting actin dynamics (Fairn and McMaster 2008), regulating phosphoinositides levels, and/or by regulating the assembly/stability of MCSs.

The involvement of OSBP, ORPs, and OSHs in the assembly/stabilization of MCSs has been shown in mammals and yeast. Osh2p and Osh3p, which both contain a FFAT motif and a PH domain, might stabilize ER-PM MCSs, through interaction with $\mathrm{Scs} 2 \mathrm{p}$, the yeast homolog of VAP-A/B on the ER, and PI4P on the PM (Stefan et al. 2011). Similarly, OSBP might stabilize ER-Golgi MCSs, thereby facilitating ERto-Golgi ceramide transport in the presence of 25-hydroxycholesterol (25OH) (Perry and Ridgway 2006), whereas ORPL1 may stabilize ERlate endosome MCSs under low cholesterol conditions (Rocha et al. 2009).

Osh proteins may also regulate sterol transport via their effect on phosphoinositide levels. It was previously shown that inactivation of different Osh proteins modulates phosphoinositide levels in various membrane compartments, including the Golgi complex, PM, and the ER (Raychaudhuri and Prinz 2010). Remarkably, inactivation of Osh4p, the most abundant Osh protein in yeast (30,000 copies per cell), increases PI4P levels in the Golgi complex. Osh4p is localized to the Golgi complex in a PI4P-dependent manner, and its inactivation bypasses the requirement for Sec14p, a PI/PCtransfer protein (Li et al. 2002). Strikingly, recent studies suggest that Osh4p functions as both sterol-transfer and PI4P-transfer proteins. Further crystal structure analysis of the Osh4pPI4P complex suggests that the PI4P-binding site overlaps with the sterol-binding site and that these two ligands can compete with each 
Lipid Transport from the ER

other (de Saint-Jean et al. 2011). Accordingly, it was proposed that Osh4p acquires PI4P at the Golgi complex and exchanges it for a sterol at the ER. This leads to the transfer of sterol from the ER to the Golgi, up the concentration gradient, and of PI4P from the Golgi to the ER, where the PI4P phosphatase Sac1 is localized. Osh4p, like its other family members, interacts with Saclp and stimulates its activity (Stefan et al. 2011). Hence, activation of Sacl at the ER, possibly via Osh4p interaction, would facilitate the hydrolysis of PI4P and consequently elevate the level of PI (Levine 2011). PI may then be transported from the ER to the Golgi, by PI-transfer protein, such as Sec14p, where it can be phosphorylated by PI4-kinase, such as Pik1, to produce PI4P. Indeed, previous studies suggest that the major function of Osh4p is to regulate the PI4P levels in the Golgi (Fairn et al. 2007), and that inactivation of OSH4 restores the PI4P levels in the Golgi of either Pik1 or Sec14 mutants (Fang et al. 1996; Li et al. 2002; Fairn et al. 2007). Yet, the function of its sterolbinding/transfer activity is not completely understood. Although it is possible that Osh4p functions as a $\mathrm{PI} 4 \mathrm{P} /$ sterol-exchange protein (de Saint-Jean et al. 2011), recent studies suggest that sterols are inhibitory ligands of Osh4p activity, and not transported cargo (Beh et al. 2012). Regardless of the specific role of sterols as transported cargo or inhibitory ligands, it is clear that the dual lipid-binding capability of Osh4 promotes coordinated distribution of phosphoinositides and sterols between cellular membranes. Other LTPs might play a similar regulatory role in coordinating lipid distribution (Peretti et al. 2008), and thereby could influence diverse membrane trafficking and signal transduction events, as well as local lipid metabolism. The transport of ceramide from the $\mathrm{ER}$, for example, which is required for SM biosynthesis at the trans-Golgi, is mediated by CERT and influenced by sterols $(25 \mathrm{OH})$ and phosphoinositides (PI4P). The distribution of $25 \mathrm{OH}$ and PI4P markedly affects the transport of ceramide by CERT, and could be regulated by other LTPs, such as OSBP and the PI-transfer domain-containing protein, Nir2 (Funato and Riezman 2001; Perry and Ridgway 2006; Peretti et al. 2008). Hence, the distribution of sterols $(25 \mathrm{OH})$ and phosphoinositides (PI4P) affects SM biosynthesis.

\section{NONVESICULAR TRANSPORT OF PHOSPHOLIPIDS IN INTACT CELLS}

Given that phospholipids are the major constituents of most biological membranes as well as transport vesicles, vesicular transport must play an important role in bulk movement of phospholipids between intracellular organelles. Yet, vesicular transport cannot provide a fine mechanism that rapidly and locally modifies the levels of certain phospholipids. This is especially critical in various signal transduction cascades of cell-surface receptors, which require rapid production and turnover of phospholipid second messengers, in particular, of phosphoinositides (Toker 2002). The involvement of LTPs in receptor-mediated signal transduction cascades has been shown by many studies (Cockcroft 1997, 1998; Wang et al. 2005). Most remarkable is the role of PITPs, which facilitate the monomeric exchange of either PI or PC between membranes in vitro. PITPs show a higher affinity for PI (16-fold) as compared to PC, and therefore are designated PITPs (Wirtz 1997, 2006). Based on their size and domain composition, PITPs can be classified into two major groups: small proteins with a single PI-transfer domain (PITD), such as PITP $\alpha$ and PITP $\beta$ in mammals and Sec14p in yeast, and larger proteins consisting of a PITD and additional structural domains of different functions, such as Nir2 and Nir3 in mammals and RdgB in Drosophila (Lev et al. 1999; Cockcroft 2001; Lev 2004). Extensive studies on PITP $\alpha$ and $\beta$ in mammalian cells suggest that they are involved in $\mathrm{PI}(4,5) \mathrm{P} 2$ synthesis in response to growth factor and G-protein-coupled receptors stimulation (Cunningham et al. 1995; KauffmannZeh et al. 1995), possibly by supplying PI from the ER to the PM. This model was supported by both genetic and physiological studies on $\mathrm{RdgB}$ in Drosophila and its role in phototransduction cascade (Harris and Stark 1977; Vihtelic et al. 1991, 1993; Hardie et al. 2001). Nevertheless, other studies suggest that PITPs are 
S. Lev

not involved in PI transport to the PM (Milligan et al. 1997; Li et al. 2000), and more recently, that PI could be delivered to the PM by specialized membrane compartments that carry PIS (Kim et al. 2011). Studies on Sec14p, the major PITP in budding yeast, also suggest that it does not act as PI/PC-transfer protein in intact cells, but rather, as a scaffold that regulates the production of phosphoinositides and PC (Bankaitis et al. 2010). However, the exact mechanism underlying this mode of action has not been fully resolved, and could possibly involve physical interaction with enzymes/regulators of the PC and/or phosphoinositide biosynthesis pathways. However, such interactions have not been characterized, and despite the described interactions between PITP $\alpha$, PI3K (Panaretou et al. 1997; Jones et al. 1998), and PI4K (Kauffmann-Zeh et al. 1995), these interactions have not been further investigated at the molecular level. Hence, the mechanisms by which PITPs regulate phosphoinositides and PC metabolism are not completely understood and require further investigation.

\section{CONCLUDING REMARKS}

In this article, we describe the major biosynthesis pathways of GPLs, sphingolipids, and sterols at the ER of mammalian cells, as well as the mechanisms by which these lipids are delivered to different cellular membranes. We focus on nonvesicular lipid transport and discuss the role of LTPs in this transport route both in vitro and in intact cells. Our major conclusions are:

(a) Nonvesicular lipid transport mediates transport of lipids from their synthesis site ER to different target membranes.

(b) The transport of sterols and ceramide from the ER is predominantly mediated by nonvesicular lipid transport both in yeast and mammals.

(c) Nonvesicular lipid transport between cellular membranes can be mediated by spontaneous lipid transport or by LTPs.

(d) Spontaneous lipid transport is thought to be greatly enhanced at MCSs; small cyto- solic gaps between the ER membranes and virtually all other cellular organelles.

(e) LTPs markedly facilitate (in several orders of magnitude) the transport of lipids between membranes in vitro.

(f) LTPs bind lipid monomers in a hydrophobic pocket and share a common mechanism of lipid transfer in vitro.

(g) LTPs do not mediate a simple vectorial lipid transport from one membrane to another. Rather, they facilitate lipid transport between membranes according to their membrane environment.

(h) LTPs modulate the local distribution of specific membrane lipids, thereby regulating various cellular processes including vesicular trafficking, signal transduction, and lipid metabolism.

(i) Further studies on nonvesicular lipid trafficking and on LTPs are required to better understand how lipid are transported from the ER and distinctly distributed between biological membranes, and how these processes are influenced by LTPs.

\section{ACKNOWLEDGMENTS}

Sima Lev is the incumbent of the Joyce and Ben B. Eisenberg Chair of Molecular Biology and Cancer Research. This work is supported by the Israel Science Foundation, Grant No. 548/ 08, and by the Israel Cancer Association.

\section{REFERENCES}

Alpy F, Tomasetto C. 2005. Give lipids a START: The StARrelated lipid transfer (START) domain in mammals. J Cell Sci 118: 2791-2801.

Antonsson B. 1997. Phosphatidylinositol synthase from mammalian tissues. Biochim Biophys Acta 1348: 179186.

Balla T, Szentpetery Z, Kim YJ. 2009. Phosphoinositide signaling: New tools and insights. Physiology (Bethesda) 24: 231-244.

Bankaitis VA, Mousley CJ, Schaaf G. 2010. The Sec14 superfamily and mechanisms for crosstalk between lipid metabolism and lipid signaling. Trends Biochem Sci 35: 150160. 
Baumann NA, Sullivan DP, Ohvo-Rekila H, Simonot C, Pottekat A, Klaassen Z, Beh CT, Menon AK. 2005. Transport of newly synthesized sterol to the sterol-enriched plasma membrane occurs via nonvesicular equilibration. Biochemistry 44: 5816-5826.

Beh CT, McMaster CR, Kozminski KG, Menon AK. 2012. A detour for yeast oxysterol-binding proteins. J Biol Chem 287: $11481-11488$.

Benning C, Xu C, Awai K. 2006. Nonvesicular and vesicular lipid trafficking involving plastids. Curr Opin Plant Biol 9: 241-247.

Blom T, Somerharju P, Ikonen E. 2011. Synthesis and biosynthetic trafficking of membrane lipids. Cold Spring Harb Perspect Biol 3: a004713.

Borgese N, Francolini M, Snapp E. 2006. Endoplasmic reticulum architecture: Structures in flux. Curr Opin Cell Biol 18: $358-364$.

Cockcroft S. 1997. Phosphatidylinositol transfer proteins: Requirements in phospholipase $\mathrm{C}$ signaling and in regulated exocytosis. FEBS Lett 410: 44-48.

Cockcroft S. 1998. Phosphatidylinositol transfer proteins: A requirement in signal transduction and vesicle traffic. Bioessays 20: $423-432$.

Cockcroft S. 2001. Phosphatidylinositol transfer proteins couple lipid transport to phosphoinositide synthesis. Semin Cell Dev Biol 12: 183-191.

Cunningham E, Thomas GM, Ball A, Hiles I, Cockcroft S. 1995. Phosphatidylinositol transfer protein dictates the rate of inositol trisphosphate production by promoting the synthesis of PIP2. Curr Biol 5: 775-783.

D’Angelo G, Polishchuk E, Di Tullio G, Santoro M, Di Campli A, Godi A, West G, Bielawski J, Chuang CC, van der Spoel AC, et al. 2007. Glycosphingolipid synthesis requires FAPP2 transfer of glucosylceramide. Nature 449: 62-67.

D’Angelo G, Vicinanza M, De Matteis MA. 2008. Lipidtransfer proteins in biosynthetic pathways. Curr Opin Cell Biol 20: $360-370$.

Dawidowicz EA. 1987. Dynamics of membrane lipid metabolism and turnover. Annu Rev Biochem 56: 43-61.

de Brito OM, Scorrano L. 2008. Mitofusin 2 tethers endoplasmic reticulum to mitochondria. Nature 456: $605-$ 610.

de Saint-Jean M, Delfosse V, Douguet D, Chicanne G, Payrastre B, Bourguet W, Antonny B, Drin G. 2011. Osh4p exchanges sterols for phosphatidylinositol 4phosphate between lipid bilayers. J Cell Biol 195: 965978.

Fagone P, Jackowski S. 2009. Membrane phospholipid synthesis and endoplasmic reticulum function. J Lipid Res 50: $\mathrm{S} 311-\mathrm{S} 316$.

Fairn GD, McMaster CR. 2008. Emerging roles of the oxysterol-binding protein family in metabolism, transport, and signaling. Cell Mol Life Sci 65: 228-236.

Fairn GD, Curwin AJ, Stefan CJ, McMaster CR. 2007. The oxysterol binding protein Keslp regulates Golgi apparatus phosphatidylinositol-4-phosphate function. Proc Natl Acad Sci 104: 15352-15357.

Fang M, Kearns BG, Gedvilaite A, Kagiwada S, Kearns M, Fung MK, Bankaitis VA. 1996. Keslp shares homology with human oxysterol binding protein and participates in a novel regulatory pathway for yeast Golgi-derived transport vesicle biogenesis. EMBO J 15: 6447-6459.

Feng L, Chan WW, Roderick SL, Cohen DE. 2000. Highlevel expression and mutagenesis of recombinant human phosphatidylcholine transfer protein using a synthetic gene: Evidence for a C-terminal membrane binding domain. Biochemistry 39: 15399-15409.

Funato K, Riezman H. 2001. Vesicular and nonvesicular transport of ceramide from ER to the Golgi apparatus in yeast. J Cell Biol 155: 949-959.

Gadella TW Jr, Wirtz KW. 1994. Phospholipid binding and transfer by the nonspecific lipid-transfer protein (sterol carrier protein 2). A kinetic model. Eur J Biochem 220: 1019-1028.

Giorgi C, De Stefani D, Bononi A, Rizzuto R, Pinton P. 2009. Structural and functional link between the mitochondrial network and the endoplasmic reticulum. Int J Biochem Cell Biol 41: 1817-1827.

Halter D, Neumann S, van Dijk SM, Wolthoorn J, de Maziere AM, Vieira OV, Mattjus P, Klumperman J, van Meer G, Sprong H. 2007. Pre- and post-Golgi translocation of glucosylceramide in glycosphingolipid synthesis. J Cell Biol 179: 101-115.

Hanada K. 2003. Serine palmitoyltransferase, a key enzyme of sphingolipid metabolism. Biochim Biophys Acta 1632: $16-30$.

Hanada K, Kumagai K, Yasuda S, Miura Y, Kawano M, Fukasawa M, Nishijima M. 2003. Molecular machinery for non-vesicular trafficking of ceramide. Nature 426: 803-809.

Hardie RC, Raghu P, Moore S, Juusola M, Baines RA, Sweeney ST. 2001. Calcium influx via TRP channels is required to maintain PIP2 levels in Drosophila photoreceptors. Neuron 30: 149-159.

Harris WA, Stark WS. 1977. Hereditary retinal degeneration in Drosophila melanogaster. A mutant defect associated with the phototransduction process. J Gen Physiol 69: 261-291.

Heino S, Lusa S, Somerharju P, Ehnholm C, Olkkonen VM, Ikonen E. 2000. Dissecting the role of the golgi complex and lipid rafts in biosynthetic transport of cholesterol to the cell surface. Proc Natl Acad Sci 97: 8375-8380.

Helmkamp GM Jr. 1986. Phospholipid transfer proteins: Mechanism of action. J Bioenerg Biomembr 18: 71-91.

Hermansson M, Hokynar K, Somerharju P. 2011. Mechanisms of glycerophospholipid homeostasis in mammalian cells. Prog Lipid Res 50: 240-257.

Holthuis JC, Levine TP. 2005. Lipid traffic: Floppy drives and a superhighway. Nat Rev Mol Cell Biol 6: 209-220.

Holthuis JC, van Meer G, Huitema K. 2003. Lipid microdomains, lipid translocation and the organization of intracellular membrane transport (Review). Mol Membr Biol 20: 231-241.

Hynynen R, Laitinen S, Kakela R, Tanhuanpaa K, Lusa S, Ehnholm C, Somerharju P, Ikonen E, Olkkonen VM. 2005. Overexpression of OSBP-related protein 2 (ORP2) induces changes in cellular cholesterol metabolism and enhances endocytosis. Biochem J 390: 273-283.

Ikonen E, Jansen M. 2008. Cellular sterol trafficking and metabolism: Spotlight on structure. Curr Opin Cell Biol 20: $371-377$. 
S. Lev

Im YJ, Raychaudhuri S, Prinz WA, Hurley JH. 2005. Structural mechanism for sterol sensing and transport by OSBP-related proteins. Nature 437: 154-158.

Jones JD, Thompson TE. 1989. Spontaneous phosphatidylcholine transfer by collision between vesicles at high lipid concentration. Biochemistry 28: 129-134.

Jones SM, Alb JG Jr, Phillips SE, Bankaitis VA, Howell KE. 1998. A phosphatidylinositol 3-kinase and phosphatidylinositol transfer protein act synergistically in formation of constitutive transport vesicles from the trans-Golgi network. J Biol Chem 273: 10349-10354.

Kaplan MR, Simoni RD. 1985a. Intracellular transport of phosphatidylcholine to the plasma membrane. J Cell Bio 101: $441-445$.

Kaplan MR, Simoni RD. 1985b. Transport of cholesterol from the endoplasmic reticulum to the plasma membrane. J Cell Biol 101: 446-453.

Kauffmann-Zeh A, Thomas GM, Ball A, Prosser S, Cunningham E, Cockcroft S, Hsuan JJ. 1995. Requirement for phosphatidylinositol transfer protein in epidermal growth factor signaling. Science 268: 1188-1190.

Kawano M, Kumagai K, Nishijima M, Hanada K. 2006. Efficient trafficking of ceramide from the endoplasmic reticulum to the Golgi apparatus requires a VAMP-associated protein-interacting FFAT motif of CERT. $J$ Biol Chem 281: 30279-30288.

Kim YJ, Guzman-Hernandez ML, Balla T. 2011. A highly dynamic ER-derived phosphatidylinositol-synthesizing organelle supplies phosphoinositides to cellular membranes. Dev Cell 21: 813-824.

Kornmann B, Currie E, Collins SR, Schuldiner M, Nunnari J, Weissman JS, Walter P. 2009. An ER-mitochondria teth ering complex revealed by a synthetic biology screen. Science 325: 477-481.

Kudo N, Kumagai K, Tomishige N, Yamaji T, Wakatsuki S, Nishijima M, Hanada K, Kato R. 2008. Structural basis for specific lipid recognition by CERT responsible for nonvesicular trafficking of ceramide. Proc Natl Acad Sci 105: 488-493.

Ladinsky MS, Mastronarde DN, McIntosh JR, Howell KE, Staehelin LA. 1999. Golgi structure in three dimensions: Functional insights from the normal rat kidney cell. J Cell Biol 144: 1135-1149.

Lalanne F, Ponsin G. 2000. Mechanism of the phospholipid transfer protein-mediated transfer of phospholipids from model lipid vesicles to high density lipoproteins. Biochim Biophys Acta 1487: 82-91.

Lebiedzinska M, Szabadkai G, Jones AW, Duszynski J, Wieckowski MR. 2009. Interactions between the endoplasmic reticulum, mitochondria, plasma membrane and other subcellular organelles. Int J Biochem Cell Biol 41: 1805-1816.

Lehto M, Olkkonen VM. 2003. The OSBP-related proteins: A novel protein family involved in vesicle transport, cellular lipid metabolism, and cell signalling. Biochim Biophys Acta 1631: 1-11.

Lev S. 2004. The role of the Nir/rdgB protein family in membrane trafficking and cytoskeleton remodeling. Exp Cell Res 297: 1-10.

Lev S. 2010. Non-vesicular lipid transport by lipid-transfer proteins and beyond. Nat Rev Mol Cell Biol 11: 739-750.
Lev S, Hernandez J, Martinez R, Chen A, Plowman G, Schlessinger J. 1999. Identification of a novel family of targets of PYK2 related to Drosophila retinal degeneration B (rdgB) protein. Mol Cell Biol 19: 2278-2288.

Lev S, Ben Halevy D, Peretti D, Dahan N. 2008. The VAP protein family: From cellular functions to motor neuron disease. Trends Cell Biol 18: 282-290.

Levine T. 2004. Short-range intracellular trafficking of small molecules across endoplasmic reticulum junctions. Trends Cell Biol 14: 483-490.

Levine TP. 2011. Lipid traffic: Osh4p makes an unexpected exchange. J Cell Biol 195: 927-929.

Levine TP, Munro S. 1998. The pleckstrin homology domain of oxysterol-binding protein recognizes a determinant specific to Golgi membranes. Curr Biol 8: 729-739.

Li X, Xie Z, Bankaitis VA. 2000. Phosphatidylinositol/phosphatidylcholine transfer proteins in yeast. Biochim Biophys Acta 1486: 55-71.

Li X, Rivas MP, Fang M, Marchena J, Mehrotra B, Chaudhary A, Feng L, Prestwich GD, Bankaitis VA. 2002. Analysis of oxysterol binding protein homologue Kes1p function in regulation of Sec14p-dependent protein transport from the yeast Golgi complex. J Cell Biol 157: 63-77.

Litvak V, Dahan N, Ramachandran S, Sabanay H, Lev S. 2005. Maintenance of the diacylglycerol level in the Golgi apparatus by the Nir2 protein is critical for Golgi secretory function. Nat Cell Biol 7: 225-234.

Loewen CJ, Roy A, Levine TP. 2003. A conserved ER targeting motif in three families of lipid binding proteins and in Opilp binds VAP. EMBO J 22: 2025-2035.

Maxfield FR, Mondal M. 2006. Sterol and lipid trafficking in mammalian cells. Biochem Soc Trans 34: 335-359.

Maxfield FR, van Meer G. 2010. Cholesterol, the central lipid of mammalian cells. Curr Opin Cell Biol 22: 422-429.

Maxfield FR, Wustner D. 2002. Intracellular cholesterol transport. J Clin Invest 110: 891-898.

Merrill AH Jr. 2002. De novo sphingolipid biosynthesis: A necessary, but dangerous, pathway. J Biol Chem 277: 25843-25846

Mesmin B, Maxfield FR. 2009. Intracellular sterol dynamics. Biochim Biophys Acta 1791: 636-645.

Mesmin B, Pipalia NH, Lund NW, Ramlall TF, Sokolov A, Eliezer D, Maxfield FR. 2011. STARD4 abundance regulates sterol transport and sensing. Mol Biol Cell 22 4004-4015.

Milligan SC, Alb JG Jr, Elagina RB, Bankaitis VA, Hyde DR. 1997. The phosphatidylinositol transfer protein domain of Drosophila retinal degeneration B protein is essential for photoreceptor cell survival and recovery from light stimulation. J Cell Biol 139: 351-363.

Ngo M, Ridgway ND. 2009. Oxysterol binding protein-related Protein 9 (ORP9) is a cholesterol transfer protein that regulates Golgi structure and function. Mol Biol Cell 20: $1388-1399$.

Nguyen TT, Lewandowska A, Choi JY, Markgraf DF, Junker M, Bilgin M, Ejsing CS, Voelker DR, Rapoport TA Shaw JM. 2012. Geml and ERMES do not directly affect phosphatidylserine transport from ER to mitochondria or mitochondrial inheritance. Traffic 13: 880-890. 
Nichols JW. 1988. Phospholipid transfer between phosphatidylcholine-taurocholate mixed micelles. Biochemistry 27: 3925-3931.

Odorizzi G, Babst M, Emr SD. 2000. Phosphoinositide signaling and the regulation of membrane trafficking in yeast. Trends Biochem Sci 25: 229-235.

Ozeki S, Cheng J, Tauchi-Sato K, Hatano N, Taniguchi H, Fujimoto T. 2005. Rab18 localizes to lipid droplets and induces their close apposition to the endoplasmic reticulum-derived membrane. J Cell Sci 118: 2601-2611.

Pagano RE. 1988. What is the fate of diacylglycerol produced at the Golgi apparatus? Trends Biochem Sci 13: 202-205.

Panaretou C, Domin J, Cockcroft S, Waterfield MD. 1997. Characterization of p150, an adaptor protein for the human phosphatidylinositol (PtdIns) 3-kinase. Substrate presentation by phosphatidylinositol transfer protein to the p150.Ptdins 3-kinase complex. J Biol Chem 272: 2477-2485.

Peretti D, Dahan N, Shimoni E, Hischberg K, Lev S. 2008. Coordinated lipid transfer between the endoplasmic reticulum and the Golgi complex requires the VAP proteins and is essential for Golgi-mediated transport. Mol Biol Cell 19: 3871-3884.

Perkins G, Renken C, Martone ME, Young SJ, Ellisman M, Frey T. 1997. Electron tomography of neuronal mitochondria: Three-dimensional structure and organization of cristae and membrane contacts. JStructBiol 119:260-272.

Perry RJ, Ridgway ND. 2006. Oxysterol-binding protein and vesicle-associated membrane protein-associated protein are required for sterol-dependent activation of the ceramide transport protein. Mol Biol Cell 17: 2604-2616.

Prosser S, Sarra R, Swigart P, Ball A, Cockcroft S. 1997. Deletion of 24 amino acids from the C-terminus of phosphatidylinositol transfer protein causes loss of phospholipase C-mediated inositol lipid signalling. Biochem J 324: $19-23$.

Raychaudhuri S, Prinz WA. 2010. The diverse functions of oxysterol-binding proteins. Annu Rev Cell Dev Biol 26: 157-177.

Raychaudhuri S, Im YJ, Hurley JH, Prinz WA. 2006. Nonvesicular sterol movement from plasma membrane to ER requires oxysterol-binding protein-related proteins and phosphoinositides. J Cell Biol 173: 107-119.

Rocha N, Kuijl C, van der Kant R, Janssen L, Houben D, Janssen H, Zwart W, Neefjes J. 2009. Cholesterol sensor ORP1L contacts the ER protein VAP to control Rab7RILP-p150 Glued and late endosome positioning. J Cell Biol 185: 1209-1225.

Rodriguez-Agudo D, Ren S, Wong E, Marques D, Redford K, Gil G, Hylemon P, Pandak WM. 2008. Intracellular cholesterol transporter StarD4 binds free cholesterol and increases cholesteryl ester formation. J Lipid Res 49: 14091419.

Rueckert DG, Schmidt K. 1990. Lipid transfer proteins. Chem Phys Lipids 56: 1-20.

Schouten A, Agianian B, Westerman J, Kroon J, Wirtz KW, Gros P. 2002. Structure of apo-phosphatidylinositol transfer protein $\alpha$ provides insight into membrane association. EMBO J 21: 2117-2121.

Schulz TA, Choi MG, Raychaudhuri S, Mears JA, Ghirlando R, Hinshaw JE, Prinz WA. 2009. Lipid-regulated sterol transfer between closely apposed membranes by oxysterol-binding protein homologues. J Cell Biol 187: 889-903.

Sha B, Phillips SE, Bankaitis VA, Luo M. 1998. Crystal structure of the Saccharomyces cerevisiae phosphatidylinositol-transfer protein. Nature 391: 506-510.

Shadan S, Holic R, Carvou N, Ee P, Li M, Murray-Rust J, Cockcroft S. 2008. Dynamics of lipid transfer by phosphatidylinositol transfer proteins in cells. Traffic 9: $1743-1756$.

Shore GC, Tata JR. 1977. Two fractions of rough endoplasmic reticulum from rat liver. I. Recovery of rapidly sedimenting endoplasmic reticulum in association with mitochondria. J Cell Biol 72: 714-725.

Simons K, Ikonen E. 2000. How cells handle cholesterol. Science 290: 1721-1726.

Sprong H, van der Sluijs P, van Meer G. 2001. How proteins move lipids and lipids move proteins. Nat Rev Mol Cell Biol 2: 504-513.

Stefan CJ, Manford AG, Baird D, Yamada-Hanff J, Mao Y, Emr SD. 2011. Osh proteins regulate phosphoinositide metabolism at ER-plasma membrane contact sites. Cell 144: 389-401.

Stone SJ, Vance JE. 2000. Phosphatidylserine synthase- 1 and -2 are localized to mitochondria-associated membranes. J Biol Chem 275: 34534-34540.

Sullivan DP, Ohvo-Rekila H, Baumann NA, Beh CT, Menon AK. 2006. Sterol trafficking between the endoplasmic reticulum and plasma membrane in yeast. Biochem Soc Trans 34: 356-358.

Tilley SJ, Skippen A, Murray-Rust J, Swigart PM, Stewart A, Morgan CP, Cockcroft S, McDonald NQ. 2004. Structure-function analysis of human [corrected] phosphatidylinositol transfer protein $\alpha$ bound to phosphatidylinositol. Structure (Camb) 12: 317-326.

Tobert JA. 2003. Lovastatin and beyond: The history of the HMG-CoA reductase inhibitors. Nat Rev Drug Discov 2: 517-526.

Toker A. 2002. Phosphoinositides and signal transduction. Cell Mol Life Sci 59: 761-779.

Tremblay JM, Voziyan PA, Helmkamp GM Jr, Yarbrough LR. 1998. The C-terminus of phosphatidylinositol transfer protein modulates membrane interactions and transfer activity but not phospholipid binding. Biochim Biophys Acta 1389: 91-100.

Urbani L, Simoni RD. 1990. Cholesterol and vesicular stomatitis virus $G$ protein take separate routes from the endoplasmic reticulum to the plasma membrane. J Biol Chem 265: 1919-1923.

Vance JE. 2008. Phosphatidylserine and phosphatidylethanolamine in mammalian cells: Two metabolically related aminophospholipids. J Lipid Res 49: 1377-1387.

Vance JE, Steenbergen R. 2005. Metabolism and functions of phosphatidylserine. Prog Lipid Res 44: 207-234.

Vance JE, Aasman EJ, Szarka R. 1991. Brefeldin A does not inhibit the movement of phosphatidylethanolamine from its sites for synthesis to the cell surface. J Bio Chem 266: 8241-8247.

van Meer G, Voelker DR, Feigenson GW. 2008. Membrane lipids: Where they are and how they behave. Nat Rev Mol Cell Biol 9: 112-124. 
S. Lev

Vihtelic TS, Hyde DR, O’Tousa JR. 1991. Isolation and characterization of the Drosophila retinal degeneration B (rdgB) gene. Genetics 127: 761-768.

Vihtelic TS, Goebl M, Milligan S, O’Tousa JE, Hyde DR. 1993. Localization of Drosophila retinal degeneration B, a membrane-associated phosphatidylinositol transfer protein. J Cell Biol 122: 101310-101322.

Voelker DR. 1990. Lipid transport pathways in mammalian cells. Experientia 46: 569-579.

Voekler DR. 2009. Genetic and biochemical analysis of non-vesicular lipid traffic. Annu Rev Biochem 78: 827856.

Wang PY, Weng J, Anderson RG. 2005. OSBP is a cholesterolregulated scaffolding protein in control of ERK $1 / 2$ activation. Science 307: 1472-1476.
Wirtz KW. 1997. Phospholipid transfer proteins revisited. Biochem J 324: 353-360.

Wirtz KW. 2006. Phospholipid transfer proteins in perspective. FEBS Lett 580: 5436-5441.

Wirtz KW, Zilversmit DB. 1968. Exchange of phospholipids between liver mitochondria and microsomes in vitro. J Biol Chem 243: 3596-3602.

Wirtz KW, Schouten A, Gros P. 2006. Phosphatidylinositol transfer proteins: From closed for transport to open for exchange. Adv Enzyme Regul 46: 301-311.

Yoder MD, Thomas LM, Tremblay JM, Oliver RL, Yarbrough LR, Helmkamp GM Jr. 2001. Structure of a multifunctional protein. Mammalian phosphatidylinositol transfer protein complexed with phosphatidylcholine. J Biol Chem 276: 9246-9452. 


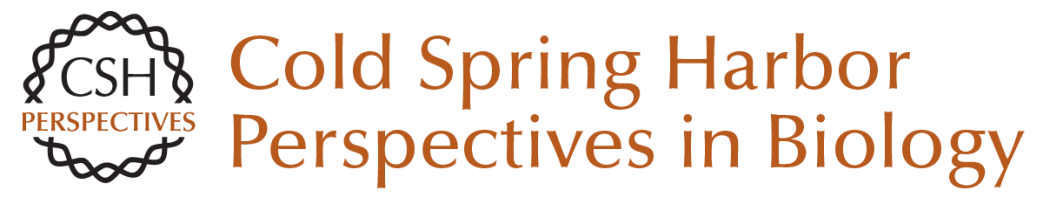

\section{Nonvesicular Lipid Transfer from the Endoplasmic Reticulum}

Sima Lev

Cold Spring Harb Perspect Biol 2012; doi: 10.1101/cshperspect.a013300

Subject Collection The Endoplasmic Reticulum

Sorting and Export of Proteins at the Endoplasmic Reticulum

Ishier Raote, Sonashree Saxena and Vivek Malhotra

Endoplasmic Reticulum Membrane Contact Sites, Lipid Transport, and Neurodegeneration Andrés Guillén-Samander and Pietro De Camilli

AMPylation and Endoplasmic Reticulum Protein Folding Homeostasis

Luke A. Perera and David Ron

The Endoplasmic Reticulum and the Fidelity of Nascent Protein Localization

Michael J. McKenna and Sichen Shao

Endoplasmic Reticulum Architecture and Inter-Organelle Communication in Metabolic Health and Disease

Ana Paula Arruda and Günes Parlakgül

Regulation and Functions of the ER-Associated

Nrf1 Transcription Factor

Gary Ruvkun and Nicolas Lehrbach

Mechanism of Protein Translocation by the Sec61

Translocon Complex

Samuel Itskanov and Eunyong Park

Evolutionary Aspects of the Unfolded Protein

Response

Kazutoshi Mori
Glycerolipid Synthesis and Lipid Droplet

Formation in the Endoplasmic Reticulum

Robert V. Farese, Jr. and Tobias C. Walther

The Biogenesis of Multipass Membrane Proteins Luka Smalinskaite and Ramanujan S. Hegde

A TAle of Two Pathways: Tail-Anchored Protein Insertion at the Endoplasmic Reticulum Alina Guna, Masami Hazu, Giovani Pinton Tomaleri, et al.

Cholesterol Transport to the Endoplasmic

Reticulum John P. Kennelly and Peter Tontonoz

The Role of the Rhomboid Superfamily in ER

Protein Quality Control: From Mechanisms and

Functions to Diseases

Satarupa Bhaduri, Nicola A. Scott and Sonya E. Neal

ER-Phagy: Quality and Quantity Control of the

Endoplasmic Reticulum by Autophagy Haruka Chino and Noboru Mizushima

Structure and Function of the Nuclear Pore Complex

Stefan Petrovic, George W. Mobbs, Christopher J. Bley, et al.

Post-Translational Regulation of HMG CoA

Reductase

Youngah Jo and Russell A. DeBose-Boyd

For additional articles in this collection, see http://cshperspectives.cshlp.org/cgi/collection/

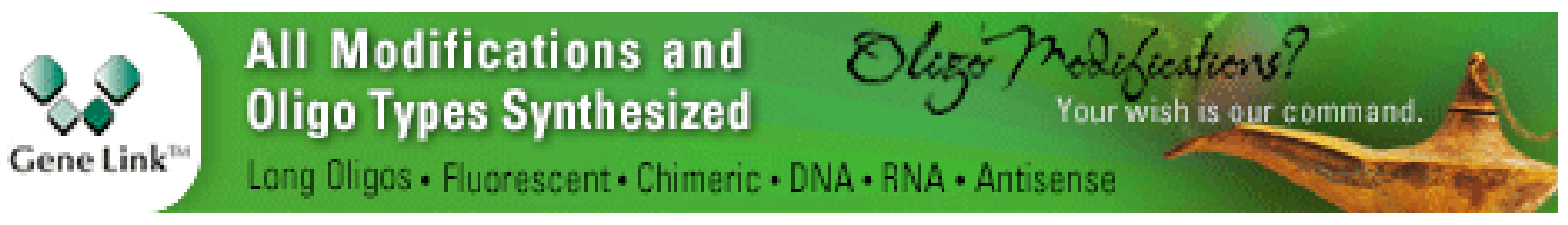


For additional articles in this collection, see http://cshperspectives.cshlp.org/cgi/collection/

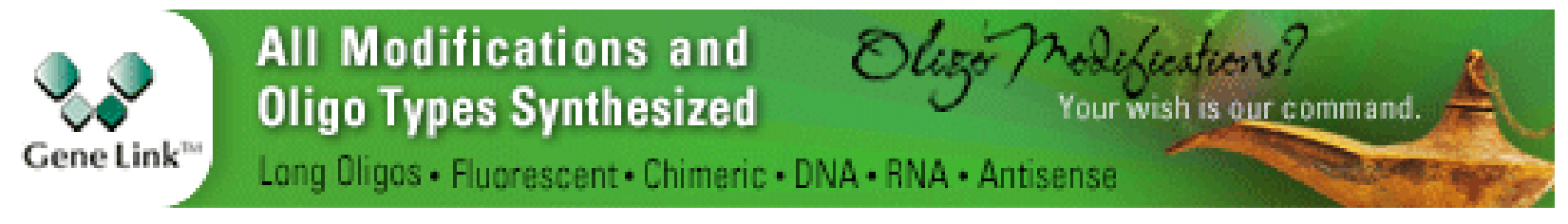

Copyright @ 2012 Cold Spring Harbor Laboratory Press; all rights reserved 